\title{
High Concept en el escenario del Pitch: Herramientas de seducción en el mercado de proyectos fílmicos
}

\begin{abstract}
Resumen / High concept en el escenario del pitch: herramientas de seducción en el mercado de proyectos fílmicos

En losúltimosaños se ha instalado un recurso conceptual en virtud de la dialéctica concéntrica de proyectos y desarrollos de corte ficcional, bajo la premisa de generar un fluido feedback entre el circuito ejecutivocreativo, mediante el sistema catalizador del High Concept. El ensayo ahonda losesquemas de fuentes de información paradigmáticas que resultan operativas para este sistema emergente, que ya cuenta con pautas concretas y resultados satisfactorios para ambas partes en el marco de la comercialización y desarrollo de ideas con potencial fílmico.
\end{abstract}

\section{Palabras claves}

comunidad de espectadores - eventos e incidentes - línea de deseo - motivo recurrente - pitch session procedimiento de presentación - script editor - tratamiento.

\section{Summary / High Concept in the scenery of Pitch: convincing tools in the market of filming proyects}

Over the past years a conceptual resource on the advantages of dialetics concentric of projects and developments of a partial cut, under the premise of generating a fluid feedback between the executivecreative circle, through the catalizing system of High Concept has been install. The essay deepens inside source's diagrams of paradigmatic information, that results effective for this system which already counts with specific rulesand satifactory resultsfor boths partsin the frame of commercialization and development of ideas with potencial filming.

\section{Key w ords}

audience community - events and incidents - pitch session - presentation's procedure - recurrent motive script editor - treatement - wish line.

\section{Resumo / High concept no cenário do pitch: Ferramentas de seduçaõ no mercado de projetos filmicos}

Nosúltimosanos se ha instalado um recurso conceptual na dialética concêntrica de projetos e realizações de caráter ficcional, sobre a premissa de gerar um fluido feedback entre o circuito executivo-criativo, mediante o sistema catalizador do High Concept. O ensaio profundiza osesquemas de fontes de informação paradigmáticas, que resultam operativas para este sistema emergente, que conta com pautas concretase resultados satisfatórios para ambas partes, no marco da comercialização e o desenvolvimento de idéias com potencial fílmico.

\section{Palavras chave}

comunidade de espectadores - eventos - incidentes - linha de desejo - motivo recurrente - pitch session procedimento de presentação - script editor.

\footnotetext{
* Centro de Estudios en Diseño y Comunicación, Facultad de Diseño y Comunicación, Universidad de Palermo. infocedyc@palermo.edu Fabián Iriarte: Director y Guionista cinematográfico. Profesor de la Facultad de Diseño y Comunicación de la UP.
} 
Entre la liviandad de una estimulante presunción primaria y la creencia fundamentada en la propiedad de asignarle una responsabilidad solitaria al impacto de una creación, sin tener en cuenta el crédito psíquico-físico-intelectual que requiere el marco de concertación y devolución racional de la obra defendida, se erige un mercado emergente estructurado, en la base de pautas relacionantes cuyo objetivo es marcar un vínculo significante entre el creador expositor y el ejecutivo productor -solicitante.

Cuando un autor abandona necesariamente el ámbito creativo y para transitar los caminos del marketing, pocos elementos paradigmáticos encontrará. Aunque el film ocupe más de un tercio de sus pensamientos, aunque creamos que la historia está claramente perfilada, que es una gran idea y que cualquier productor lúcido entenderá que es la propuesta comercial de su vida, nada dará mas seguridad que dominar el intrincado pero inexcusable High Concept y su proyección sintomática: el Pitch.

El ambiguo deseo de establecer relaciones directas con posibles facilitadores 0 hacedores de proyectos se convierte en una perspectiva subjetiva cuando lo enfrentamos a un criterio globalizador tendiente a concentrar en eventos reglamentados como Pitch Festivals and Pitching Professional Session, la posibilidad multilateral de establecer y focalizar las apetencias temáticas de grandes estudios y productoras independientes en un mismo ámbito y con el mismo grado de afectación y recursos entre las partes. Pero, en el intrincado ámbito de la comercialización, bien es sabido que en los intereses aleatorios de los grandes estudios no configura íntegramente el recurso de los Pitch Festivals como elemento prioritario dentro de sus filas mas emblemáticas de Departamentos Ejecutivos y Financieros. En síntesis: las grandes productoras no se caracterizan por leer cientos de páginas sin antes asegurarse que valga la pena hacerlo, mientras, el creador exponencial debe catalizar ciertas referencias del mercado para acceder a las ambiguos y mitológicos cánones de posicionamiento personal, (garantizando en el transcurso fecundidad creativa) para, de esta manera, ser habilitado en el círculo privilegiado de proyectos de orden prioritario.

Es de reformular entonces, los recursos conectivos entre la soledad del autor y la posibilidad de su llegada como ofertante, frente a las signaturas expuestas como reglas imperturbables del puente informativo y aún no desarrollado en mercados tan dispersos, (en todo sentido etimológico) como los latinos.

La producción de cualquier país depende más de su proyección internacional que de su éxito interno, mientras no se entienda esto, los stands de los ejecutivos tendrán motivo para juntar polvo.

La asignatura instalada para llegar a las grandes ligas de desarrollo de un proyecto destinado a la pantalla grande o televisiva fluctúa entre algunos de estos ítems básicos.

a. El correcto formato de presentación de los proyectos como estrado unificante, tan significativo en mercados posicionados, pero de una abstracción sorprendente en nuestro medio.

b. El procedimiento de presentación personal gober- nado por patrones físicos, intelectuales y estratégicos. c. La Sociedad Interna entre autor y obra, es decir: no cabe duda que la exposición debe ser una asociación entre el conocimiento integral de la obra mas la revelación pasional de su autor como signo corporizado de su propia creación.

d. Conocimiento integral del ámbito en que será expuesto. El lugar debe ser el correcto para el género y estilo ofertado, lo cual nos lleva hacia una investigación y relevamiento sistemático de las tendencias de los Estudios o Productores.

El conocimiento estratégico de estos marcos es de carácter fundamental si es que se quiere llegar a un sistema de producción Major o simplemente, si la meta es más modesta y sólo se desea aggiornar conceptos y unificar presentaciones en el ámbito local, tan diverso y críptico, donde clasificar las ideas que llegan al receptor es una tarea acaso Kafkiana. Es necesario entender que el objetivo standarizante de presentación de proyectos no limita la creatividad ni la produce, la consolida en forma, pero obviamente no en contenido. Sólo se pretende unificar los proyectos en un marco profesional para individualizar la riqueza de aquellos que tienen la posibilidad de peregrinar hacia una etapa de desarrollo escalonado. En ese sentido, vale decir que el elemento que debemos atender es una especie de señuelo corporativo con proyección y autodeterminación sistemática sobre modelos, cada vez más rigurosos, como conductores del hecho creativo hacia una "viabilidad" pragmática dentro de un espacio calificado y calificante.

El motivo recurrente de nuestro proceder es peligrosamente anarquizante, porque tenemos inconvenientes genealógicos, el concepto es tan diversificante que la tendencia se debate en una zona áspera de preocupante atención. Tenemos fallas en el concepto, debemos trabajar en el High Concept para poder llegar al Pitch.

Al análisis llegamos desde algunos lugares esquematizados de vieja data que nos harán reflexionar en las zonas más significativas, para luego desarrollar conceptos que se perfilan como una tendencia axiomática, por lo menos en esta primera parte de la década.

El concepto del High Concept y el Pitch no sólo es intrínseco a la necesidad de las grandes productoras de sintetizar el mecanismo selectivo sino de un pulso propio de la época: el volumen de presentaciones se multiplican y el sistema de selección se narcotiza en los confines sombríos de un Script Editor, cada vez más saturado y precipitado en satisfacer posiciones favorables para el Estudio o cubriendo su continuidad con rechazos impertinentes.

Volviendo a la esencia conceptual, siempre recurrí a una analogía culinaria para comenzar a establecer, paradójicamente, un vínculo racional sobre este tema: "High Concept es el arte de concentrar un toro en un cubito de caldo, el Pitch es hacer de ese consomé una delicia". En general siempre tenemos algo más que el High Concept como inicio, es de suponer que hemos desarrollado algo más de la historia o posiblemente tengamos un tratamiento de 
ella, eso es nuestro toro, en nuestro cubito de caldo debemos fortalecer las posiciones mas punzantes de nuestro drama y someternos a un tratamiento especial de la premisa ¿Está todo lo que quise decir aquí? ¿Puedo explicarlo en una línea? 0 ¡A hora que lo pienso, nada de lo que me motivó a escribir esta historia está aquí! Entonces tenemos un gran problema: el toro no entró en el cubito de caldo y mucho menos obtendremos un consomé apetitoso.

Lo que verdaderamente se quiere no es tan simple de conseguir. La creatividad no se pesa en libras, ni se mide en metros, ni se distingue por su velocidad. La creatividad es causa y efecto. Es el resultado de cómo se dice algo y la manera cómo se recibe.

Me detengo por un momento en el "High Concept". A menudo, aún después de terminada la película me encuentro con autores incapacitados para explicar la premisa central en dos líneas, no encuentran el High Concept porque evidentemente nunca partieron de él, y fueron afortunados esta vez porque cumplieron la finalidad, terminaron la película y aunque después de producirla el High Concept no sea vital para esa etapa superada, si puede ser para su distribución y exhibición o para una futura coproducción.

El estudiante de Cine y Televisión se empecina en creer que es un tema circunstancial, es su defensa ante un trabajo doloroso, si no sabe establecer su High Concept sabe poco de su historia y sabe menos de su personaje.

Todos, en mayor o menor medida, eludimos esa zona, y es por el escozor que produce estar en tinieblas desde el comienzo mismo del pulso creativo. Es que es el primer síntoma que manifiesta una avanzada probabilidad de perder la identidad de la historia, que ha convivido con nosotros durante un tiempo más que prudencial. Se trata de encontrar la llave a esos problemas y no eludirlos sistemáticamente, se trata de ser paciente, rescribir, ser intuitivo y colaborar con la inspiración. La precariedad conceptual no es buena compañera hacia el camino estrecho que propone el Pitch. Este sistema de signos concéntricos debe proyectar la visualización dialéctica y el transitar de los personajes en un tiempo y espacio limitado, así como proporcionar la ilusión de un fragmento espontáneo y casual de su vida, mientras que su comportamiento, constituye los únicos parámetros de su pensamiento y de su paisaje interno.

En tanto, el sentido de High Concept puede ser capitalizado en este enunciado: es la idea más el elemento que la hace diferente. La historia merece ser identificada mediante este recurso.

Me permito hacer referencia sobre un pequeño ejercicio: a menudo pregunto cuál es el High Concept de "The Truman Show", entre variadas respuestas he seleccionado estas dos como ejemplo:

Respuesta 1: Un reality show sobre un hombre. Respuesta 2: Un niño crece durante un reality show. La primera puede inscribirse dentro de cualquier reality y establece el concepto dentro de producciones con objetivos comerciales diversos y equívocos, es genérico y no destaca, le falta el elemento que la hace diferente y un desarrollo con sentido de suceso y trascendencia temática.
La segunda es más interesante, es más específica, nos establece la pregunta del tiempo ¿Vemos al niño crecer? Igualmente adolesce de desarrollo y de objetivo-deseo correspondido con una eventual comunidad de espectadores.

Podríamos establecer el High Concept así:

"Un hombre descubre que toda su vida ha sido un reality show de gran sintonía".

¿Qué lo hace diferente?

a. Es más específica en su temporalidad, estamos hablando de una etapa concreta de un adulto y de una retrospección inevitable.

b. Ubicamos al reality show como parte de la vida del personaje, no como un ente en sí mismo.

c. Proyectamos el conflicto del hombre y nos hacemos una pregunta ¿Cómo reaccionaríamos nosotros ante tal revelación? Planteamos una incógnita ¿Cómo llega a descubrirlo?

d. Hay una manifiesta violación a la intimidad, no es cualquier reality, es uno de gran sintonía y habla de su propia vida.

Lo vital en una frase. La idea más lo que la hace diferente. Es la llave para ser escuchado. Si el ejecutivo, productor o agente cambia de posición en su silla, allí se ha establecido una coyuntura, no la desperdiciemos. Es el momento de esperar una pregunta. Terminantemente prohibido abrumar con datos. La verborrea es una mala consejera en estos momentos, menos, aquí es más. Las preguntas llegaran por decantación, la historia plantea interrogantes desde su estructura minimalista y eso es lo más adecuado en esta instancia

¿Hay humor y romance? Mucho más que eso, es emocionalmente devastadora.

¿Por qué? El director del reality tiene para con él una relación padre - hijo.

Allí aparece otra vez el elemento que hace diferente la historia, el dato no estaba implícito en el High Concept, pero se usa como impulso, un Hook en medio del meeting y en el período preciso.

En esta parcela debemos ser concientes de todos los condimentos de la historia, hay que conocer los Plot Point, (puntos de giro) como para responder si vienen mas preguntas. Lo lógico en esta situación es que el ejecutivo rápidamente intente atrapar el concepto pidiendo un trabajo escalonado remunerado y el segundo paso sería una opción por el primer Draft de guión.

En nuestro país las cosas no están tan claras. En principio no hay representantes de guionistas y pocos de autores en general. Hace poco unos inversionistas devenidos en productores mostraron interés en una serie televisiva que les propuse, después de un trato desfavorable, y con el afán de ver la idea producida, accedí a dirigir el piloto. Todo fue un error. Las reglas se hacen en el camino y la autoría y las ideas se diluyen en una red confusa de intereses económicos desalojando descarnadamente lo creativo. Los inversionistas no siempre son productores que saben como opera el mercado y por lo tanto no están a la altura de reconocer los pasos básicos de una producción. Por supuesto, también hay aisladas y felices excepciones que conviven en exitosas y productivas sociedades 
creativas.

Atrás en el tiempo, precisamente en 1997 una serie de casualidades me cruzan con los factores que determinarían un urgente replanteamiento, meditación y disgregación a la hora de desarrollar una idea, con algún potencial fílmico. Sería largo contar como en unos meses me encuentro en Burbank, Los Ángeles, trabajando como Story Board Director en una pequeña productora de un amigo que confió en mi formación como director. Mi tarea consistía en estar al lado del llustrador y proporcionarle las directrices de ángulos, profundidad de campo y planos que debía tener el Draft del Storyboard, formateado a base de meetings previos con el director del film.

Pasaba muchas horas interpretando las ideas de los demás y pocas horas quedaban para desarrollar las mías. Quería convertirme en un verdadero Storytelling (así llaman en el país del norte a los naturales contadores de historias) y aunque había dirigido y vendido algunos guiones, aún me faltaba profundizar en herramientas conceptuales que articularía mi trabajo en un sistema complejo y muy lejos de mi comprensión.

Cuando me crucé con algunos profesionales ya establecidos en la mecánica Hollywoodense me sugirieron lo contrario: debía comprender el High Concept, debía acreditarme en sesiones de Pitch, mientras tanto focalicé lo técnico desde lo conceptual. En síntesis, debía comprender la diferencia entre quien simplemente tiene una idea y alguien que sabe expresarla. Tenía que saber por qué el segundo tiene mayores posibilidades de venderla. Podía saber de qué se trataba el High Concept, pero ¿qué era el Pitch? ¿Acaso algo relacionado al béisbol?

Robert Altman en su asombroso film The Player prueba la efectividad de los grandes estudios, fundamentándose, en la exposición de un calidoscopio de pasiones, tendientes a sobrevivir un día mas, tanto como una buena idea lo permita, o una decisión acertada sustituya un cúmulo de fracasos, 0 un puesto improductivo sea evidenciado en el sitio y momento menos esperado.

Altman enuncia una hipótesis sustentada en la dudosa dispersión generada por una subasta creativa, mientras expone reiteradamente y con minuciosidad breves sesiones de pitching tan sustanciosas y paradigmáticas como perturbadoras y desafiantes. Allí se puede apreciar un desfile de autores, productores y directores ensayando la técnica de la condensación extrema de una historia, la técnica de lo sugestivo más el arte de convencer, "Tengo un minuto, cuénteme su historia en 25 palabras" decía el ejecutivo de una gran productora. Si en algo se parece esto al béisbol es que aquí lo que se "tira" es una historia que debe ser atrapada por un estudio.

Es que el Pitch es la llave para que una historia pase la etapa de formulaciones amistosas y complacientes y se instale en la oficina de una productora para ser evaluada desde sus pautas nativas, y salvo que sus nombres tengan tanta relevancia como Paul Schrader, David Mamet, Robert Towne o Bill Goodman este es el medio que se posiciona en el mercado actual como una de las herramientas de más llegada e impacto.

\section{Estado causal y nivelador entre el Pitch y el High Concept}

Cuando decidimos abordar una obra ficcional nos debatimos comúnmente entre el estado inalterado que impulsa la premisa ha ser desarrollada y la consecución hacia el estado alterado o situaciones modificantes, que nos transfieren a una delgada línea que generalmente, converge en la pérdida de identidad de la premisa original.

Es que aquello que verdaderamente se quiere expresar no es tan simple de conseguir. La creatividad no se pesa en libras, ni se mide en metros, ni se distingue por su velocidad. La creatividad es causa y efecto. Es el resultado de cómo se dice algo y la manera cómo se recibe, como mencionamos. Pero también se fundamenta en la calidad primaria de sus cepas creativas.

La estabilidad creativa se basa en la constante revisión del High Concept como recurso evaluativo que sostiene la premisa con un efecto causal y recupera situaciones que son afines al motivo unificante. De esta manera entendemos la funcionalidad del High Concept como el estandarte imaginario que delimita las funciones dramáticas a un sólo estado temático referencial y será, en definitiva, el patrón que regirá el momento crucial del Pitching.

En la etapa del desarrollo ficcional el High Concept atiza una estrategia de colaboración con el clustering que formatea el universo temático rodeando al High Concept de subtemas relacionantes. El clustering suma información de contenido temático para elaborar, inclusive, subtramas capaces de darle dinámica al tema o premisa original. Pero para llegar a Pitch ideal no sólo nos nutrimos con un claro y conciso High Concept y un ajustado clustering, es necesario prepararnos para la etapa del Outline.

\section{Outline como sintaxis del Pitch}

No hay posibilidad de delinear una obra dramática sin la esforzada tarea estructural de confeccionar una escalera dramática a base de un Outline sistemático, escueto y sintético, pero conciente del marco referencial y el pulso de la obra.

El Outline es el disparador y catalizador del High Concept y el que aportará dinámica a la premisa original mediante Beats representados por eventos e incidentes implicantes que ligarán los actos y asumirán el rol clarificante en esta etapa de desarrollo.

No es recomendable la presentación en un Pitch Session sin estos elementos constitutivos y relevantes. Aún sin tener un background de desarrollo, este proceso sumatorio y elíptico, da consistencia a la presentación y podrá cubrir las inquietudes que un interesado en la obra pueda tener.

La etapa de desarrollo sugiere una gran ventaja informativa, pero más preeminencia se tiene con el amplio conocimiento del marco donde se expone. En esos términos no sólo hay que conocer su obra sino quién está dispuesto a escucharla y qué está buscando específicamente el auditorio en términos comerciales.

El maestro Federico Fellini confirmaba sus dudas sobre la total libertad creativa del artista en el preciso 
momento de crear su obra. La exposición de una historia está sujeta a pautas preestablecidas que limitan su potencial creativo y por consiguiente la búsqueda de la verdad artística.

Sin embargo David Lynch siente que "Es necesario sentirse libre de toda reflexión, las ideas surgen, se encadenan las unas a las otras y lo que las mantienen unidas, es la euforia que despiertan en ti o la repulsión que te inspiran, en ese caso las eliminas. Si en la película partes de la fijación de unos límites que no debes sobrepasar hay muchas posibilidades que eso limite tu historia. Encontrar el tono justo de un film es excitante, no se llega a eso más que cuidando los detalles..."

El ejercicio del Pitch perfila el carácter de la obra e intima la relación de ese tandem indisoluble creadorcreación, para evitar ese distanciamiento tan común que tomará notoriedad de arrastre en el rodaje, para convertirse en un punto de no retorno que difícilmente - y contrariamente a lo que algunos piensanse pueda subsanar en otras etapas de producción. La "personalización" de esa relación es producto entonces de esa causalidad recursiva entre el Pitch y el High Concept.

\section{Relación exponencial entre estructura progresiva y universo caracterológico}

El factor imprescindible es la notificación clara y concisa entre el posicionamiento sustancial de la caracterología de los personajes y su planting formal dentro de su sistema estructural dramático progresivo y modificante.

No a la dicotomía ancestral de "construyo a través de la historia" versus "construyo a través del personaje". Sólo la permisiva interacción entre estas entelequias categoriza sus pulsaciones internas y flexibiliza su funcionamiento sintáctico.

Ambos dispositivos creativos funcionan asociados a referentes comunes que luego se convertirán en "cuerpos vitales" y motores potenciales del drama. Sobre la construcción espacio-temporal y su relación con dispositivos dramáticos de una historia sería falso decir que el artista busca el tema, el tema va madurando en él como un fruto y le impulsa hasta la configuración. No es dueño de la situación sino su vasallo, su servidor. La sensibilidad, para la necesidad de ciertos pasos lógicos y para las leyes que la rigen, sólo aparecen cuando existe la fe en un ideal, solo la fe apoya el sistema de las imágenes.

En cuanto a la posibilidad de supervivencia de una historia dentro del tiempo creativo debemos decir que el verdadero depredador es su ciclo evolutivo, un camino que debe transitar hacia el reconocimiento de su potencial, la resistencia y la duda de lo que verdaderamente representa, el marco en que debe desarrollarse y el proceso de evaluación a que debe someterse.

Es necesario rever el posicionamiento y estado de las fuentes de información y su diseminación formal dentro del esquema dramático que provee el Outline diseñado con antelación. De esta manera establecemos la situación de estado del espectador dentro de la pauta de revelación informativa que desarrollemos en el Outline. El espectador puede ser receptor "debajo del sistema informático" o "sobre el sistema informático". En el primer caso el criterio de dominio es: "No sabe cómo y debe descubrir quién" el segundo criterio de dominio corresponde a: "Sabe cómo y quién, debe descubrir por qué". El consciente manejo de estos sistemas sintetizan, organizan y estimulan una vez más el High Concept y perfeccionan el extracto conductivo del Pitch.

Si tomamos como referencia el caso "debajo del sistema informático" debemos hacer hincapié en el punto catártico de tolerancia que convive con el espectador. Sabiendo que estamos reteniendo información es menester examinar los tiempos expositivos y no reiterativos del los Hooks (interrogantes a resolver), su límite de resolución y el pulso que sostiene la historia bajo la premisa de información retenida. El preciso equilibrio de la dominancia del espectador, en un esquema inferior, se debe en la revelación estimativa de la información como una equidad evidente entre los eventos e incidentes y su mediación directa sobre el drama planteado.

El equilibrio se devela en este pensamiento de Alfred Hitchcock: "En la forma corriente de suspenso es indispensable que el público esté perfectamente informado de los elementos en presencia, sino, no hay suspenso. El drama es la vida en donde se han abandonado los momentos aburridos. El primer trabajo es crear la emoción, el segundo es preservarla. No lo dude, si alguna vez se desliza sobre el terreno de la duda y de lo confuso, refúgiese en lo conocido, en lo verdadero y en lo que ya ha sido experimentado... Una escena es o no larga de acuerdo al grado de interés que provoca en el espectador".

En este sentido, el inconsciente del espectador debe tener la capacidad y la posibilidad de reaccionar, así como reacciona libremente su parte consciente.

Sin embargo, no dejamos nunca de ser emocionados por una idea y no por la realidad que expresa la imagen en su estado más purista. Igual que la palabra vamos de lo abstracto a lo concreto, sin tener empero la libertad de concebir un imaginario que sea reabsorbido aquí en imágenes precisas. Aunque el planteamiento sea virtual, el proceso no es esencialmente cinematográfico en cuanto que va de la idea a la emoción en vez de seguir el proceso inverso.

Internándonos en el efecto Kulechov arraigado en la base del lenguaje fílmico, no se convierte en fílmico sino a partir del momento en que la relación observador-observado (y más generalmente objeto-sujeto) se efectúa sobre una relación esencialmente emocional. Por decantación es la emoción quien dispara la idea y no la idea como ente productivo de la emoción.

Si bien las imágenes no son ideas nuevas, no por ello deben ilustrar conceptos. Deben sugerir ideas disponibles, pero ya no estructuradas en el espíritu del espectador: por inhabitual que sea la idea que las imágenes ofrezcan a mi captación, la experiencia personal pronto la reconocerá y la hallará en su código personal.

El autor sabe que no es él quien elige o impone su propio estilo, sino el argumento que trata y el senti- 
miento con que se lo propone, que pretenden ser expresados de una determinada manera. Cada suceso en una página es un suceso simbólico, su verdad y realidad dependen de lo que representan, lo que importa es que la invención, la metáfora resulte la más sorprendente y más lúcida corporación posible de la realidad que pretende convocar.

Podemos considerar que el cine de ficción, más allá de posibles variaciones y combinaciones serviles al lenguaje que lo rige, está constituido por cadencias y parcelas invariables, al respecto Vladimir Propp define las funciones sintácticas de la siguiente manera: "Los elementos constantes, permanentes del cuento o ficción, son las funciones de los personajes, sean cual fueren esos personajes y sea cual fuere la manera en que esas funciones se cumplen"

Las situaciones de los personajes o las modalidades de acción varían: las funciones quedan, son idénticas. Estas funciones se combinan entre ellas dentro de las secuencias constituyendo mini-programas organizativos hacia un arrastre cadencioso entre unas y otras hasta la clausura (clímax, crisis, resolución) que recupera el estado inicial del objetivo-deseo. Desde este punto de vista, toda historia es homeostática: se limita a referir la reducción de un desorden para volverlo a su lugar. Puede ser analizada en términos de disyunción y de conjunción, de separación y de unión. A fin de cuentas, una historia está hecha de disyunciones "abusivas" que dan lugar, por transformaciones, a conjunciones "normales". Este esquema estructural, que podría servir para analizar 0 al menos esquematizar cualquier tipo de intriga, puede incluso funcionar sólo, de manera depurada, sin el ropaje de la ficción tradicional. Es preciso determinar el espectro universal de la obra para una proyección direccional de la misma con llegada mediatizante global. La única oportunidad fagocitante del producto radica en la convicción universal del material primario y en que su empatía proyectiva-temática absorberá apetencias sociales dentro de un escenario desconocido

El trabajo sobre la Línea de Deseo es un dispositivo esencial. Un ecuménico predominio de la Línea del Deseo será una de las evaluaciones mas frecuentes en las Sesiones, hay que tener en cuenta que los potenciales compradores entablan su disposición bajo una expectante distribución del producto en células multidireccionales con recepción mayoritaria y vocación de promesa inmediata.

El síntoma del conflicto debe recaer sobre la disposición del carácter central para Desear un elemento devenido en vital, con la misma intensidad que la plataforma de concurrencia a la que está destinado, su target debe corresponder con una Línea de Deseo muy fuerte, fundamentándose en fluctuaciones determinantes que el target mismo ha propuesto.

Esta Línea de Deseo es la que debe servir como la espina dorsal de la historia, y está casi siempre estimulada por derivaciones auténticas y de gran envergadura, puesto que en una plataforma de lanzamiento hacia el objetivo/deseo nuestro personaje central generalmente ha perdido de vista el valor que le ha asignado a su meta principal y debe o ambiciona recuperarlo mientras propone un nuevo sistema de valores que asume el protagonismo conducente hacia la crisis.

El deseo es una de las maneras que el público se identifica con el personaje central. A través del héroe, el público invierte su tiempo en el objetivo de la historia y se involucra en la línea de deseo con la misma intensidad.

En esta etapa de desarrollo se constituye los Puntos de Revelación, aquellos que darán la información menos esperada y que seguirán presionando la meta del personaje hasta fraccionar su tiempo y espacio a límites cercanos a la consternación masiva.

El punto es no crear desde una posición artificial sin compromiso con lo real, el punto es usar el planteamiento atractivo desde recursos genuinos asentados en lo real con potencial ficcional, de esta manera nos acercaremos a lo genuino con la verdad apetecida por una gran comunidad de emociones.

Debemos recordar que una narración es el medio por excelencia para hacer que mundos fantásticos se conviertan en particularizadas situaciones reales. También, para competir con un medio polifuncional como la televisión, la narración cinematográfica debe estimular la decisión del público meta, para seleccionar su Línea de Deseo particular y abandonar su hogar para convertir al elemento emisor como su especial manera de ver el mundo alejado de su hogar.

\section{Traslación oral de un espacio-tiempo ficcionado}

Volvemos entonces a focalizar los objetivos esenciales del Pitch y su prueba vital de comunicar en un tiempo límite, un espacio-tiempo ficción de mayor envergadura proyectando (y provocando) los mecanismos imaginativos de un receptor oral sumido en una escénica diversa y restrictiva. Si tenemos en cuenta que el espacio-tiempo vital de un Pitch es de siete minutos máximo, la condensación del espaciotiempo ficción de ciento veinte páginas de un guión desarrollado, entra en una etapa de selección estricta cara a cualquier autor.

Lo expuesto anteriormente sobre el posicionamiento y desarrollo de fuentes de información solo tiene asidero si encuentra terreno fértil en el espacio tiempo ficción que debemos exponer. El manejo de estos dispositivos creativos debe funcionar orgánicamente más que estimular su pretensión desde su estamento de recurso de formula tendiente a provocar reiteradamente colapsos creativos.

La narración con sustancia sólo se nota cuando se logra los resultados que uno pretende con extrema facilidad, pero recorriendo los caminos más arduos y difíciles, un ejemplo: observemos a un principiante que juega tenis, tiene los aires de quien esta escalando una montaña, observe a un campeón, parece que todo lo desliza suavemente y sin esfuerzo.

Lo que verdaderamente pretendemos es crear el espacio ilusorio desde una naturalidad manifiesta despojada de artificios, así si hay método, que no se advierta. Ensayo un axioma que pretende esclarecer lo antedicho: "Ileguemos desde un paradigma, evitemos que se note bajo el manto valiente de lo veraz, lo sincero y pasional". 
No hay posibilidad alguna de que la historia se instale sin el gobierno conciente de los Plots Points, los Hook, Plots Secundarios y Complementarios que junto a las Unidades Temáticas, deben encontrar el correcto disparador dramático, que nos proyecte una historia con el atractivo diferente que necesitamos para convencer y convencernos de ella.

\section{Sobre el orden constitutivo de la narración cinematográfica}

Eagle enunciaba: el nivel de una obra de arte es tanto más alta cuando mas profundamente disimulada está la idea que la obra expresa.

La relación entre la complejidad de una obra y el Pitch es que este significa un elemento probatorio de la esencia más insondable del tema, al mismo tiempo que formula su atributo ecuménico y su razón productiva. Si una historia no puede ser contada desde su perfil racional difícilmente será "atendida" para encargar su desarrollo y no tendrá oportunidad de ser "adoptada" para su producción.

Las historias no acabadas desde la concepción del High Concept son corrientes en nuestra cinematografía. Un síntoma que se reproduce constantemente desde las pulsaciones no correspondidas a la historia propuesta. A cada historia le corresponde un pulso (dinámica temporal y psicológica), un perfil inductivo (medios dogmáticos que sirven a la historia como disparador y catalizador) y, un objetivo motivante (el objetivo que provoca el movimiento central y su método persuasivo para llegar a él), cuando no se encuentra el pulso de la narración, ésta se mueve en zonas erróneas, entre la duda y la exposición incongruente de situaciones, sin recurso informativo ni potencial dramático. Cuando el perfil inductivo no está lo suficientemente justificado, la apatía se une a la exposición incongruente y la historia no llega a destino, por reacción, el objetivo motivante abandona definitivamente el interés primario de la obra dejando la premisa dramática original en un rincón oscuro e intrascendente.

Habitualmente hay films encomendados a géneros enmarcados en clisés inevitables, ellos conducen a pulsos acaso preestablecidos por la convención y elaboran su rigurosidad desde propuestas regenerativas de perfil inductivo, que hace activa la sustancia del perfil motivante, creando la ilusión de una propuesta nueva.

Miklos Jancso dice al respecto: "Ios mecanismos simbólicos de una fábula ayudan a ser más exhaustivos, más profundos. La fábula no es realista, sino abstracta y por lo tanto universal".

\section{Universo caracterológico}

Hay que darle la oportunidad de existir a los personajes y hacer lo posible que el escritor no lo abandone. Lo que buscamos yendo al cine no es una sorpresa, sino una interpretación nueva de una historia que ya conocemos.

Lo que hace tridimensional a los personajes es el resultado de la colaboración entre el creador y la presencia espectral de su propia proyección mental, de lo que debería ser verdaderamente su personaje en el nuevo territorio ficcional. La construcción de un personaje no se acaba en la elaboración de una biografía, está mucho mas cerca de un "pequeño milagro" de connivencia que acerca el universo creativo con lo lejano de una verdadera existencia en construcción, subordinada a pulsos axiomáticos que la rigen. El resultado es el sujeto corporizado, dicha corporización se basa en la disponibilidad abierta del creador para transitar los rincones y horizontes infinitos que su sensibilidad le permite, hasta descubrir el espíritu primitivo de su personaje, la recompensa es la potestad de recolectar su comportamiento deductivo desde una zona de contacto íntima e inconmensurable.

La idea de lo infinito es inexpresable, pero el arte proporciona esa posibilidad de acercamiento, hace que lo íntimo sea perceptible, a lo absoluto sólo se accede por la fe y la actividad creadora.

Esta teoría de corporización de personajes se basa en el estado del autor y su conexión natural con el personaje, el deber traslativo de "vivir" su origen y visualizar su destino como una ruta de revelaciones conectada directamente al sentido del suceso inevitable, es producto del juego entre su Universo Declarado y su Universo no Resuelto.

El Universo Declarado asumirá el rol de presente, nos relacionará al personaje con su entorno, lo ubicará en espacio tiempo, perfilará su concepción de la vida y nos dará el indicio de un posible conflicto. El Universo no Resuelto será el condimento necesario para vitalizar el objetivo-deseo a futuro y planteará el tiempo psicológico del personaje.

\section{Hacia los patrones específicos del Pitch}

El dominio perceptivo de los Eventos e Incidentes y su planteo catalizador de la historia más sus causas y efectos, proveen la progresión necesaria para el Set-up básico dentro de una micro-exposición relacionante entre la comunidad de emociones. No hay duda que los Hooks serán los fusibles de interrogantes que deben ser suscriptos con hechos imprevisibles como contundentes. Los interrogantes formularán una escalera dramática que será exitosa en tanto y en cuanto sean satisfechos con imprevistos de mayor potencial emocional y creativo, ya que se debe llegar a la cresta del conflicto con un gran número de respuestas satisfechas y formativas de un elemento purificante de corte connatural y emocional. El High Concept será reforzado en forma estratégica por el síntoma expuesto del Plot Principal concatenando los Plots Secundarios, sólo cuando la referencia explore de forma cognoscente el perfil del opositor/antagonista.

Se debe evitar en este ciclo cualquier crónica que estime líneas complementarias de sucesos secundarios, puesto que nos llevarán hacia lo superficial, desviando el horizonte de las fuentes de información deductivas cuya meta es focalizar exclusivamente el impacto, a través de caracteres y conducta como dispositivo concéntrico del potencial dramático.

Por último, el pulso temporal debe funcionar como 
exponente del universo temático desarrollado y marcará la diferencia constitutiva de la narración. De esta manera estamos encausando la premisa original y su contenido, dentro de un marco unificante y relevante que establece una diferencia dentro de un cuadro expositivo y polifuncional como son las sesiones de Pitch.

\section{M icroestructura de las Sesiones de Pitch}

Tengamos en claro que el recurso del Pitch es una conveniencia recíproca entre los estudios, los autores y productores independientes para no invadir territorios y perder menos tiempo. Las grandes cadenas de televisión como los estudios cinematográficos, entendieron que centralizando esta especie de recolección de ideas en algunos Hots Points evitarían el bombardeo de papeles anónimos en sus escritorios. En parte lo lograron, pero no podrán evitar el trabajo de agentes (Representantes) que deben mantener su posición (y la razón de su existencia) llevándoles los proyectos de guionistas y productores ya consagrados, o por lo menos, de aquellos que llevan gran parte de su vida siendo representados y que difícilmente vayan a un Festival de Pitch para exponerse a un sitio diversificado entre primerizos y eventuales.

Así que a través de estas Sesiones, cada vez más populares y extensivas a algunos países y festivales europeos, aquellos silenciosos e independientes guionistas y productores tienen su clímax más encumbrado a la espera de una resolución satisfactoria.

La forma más simple de definir el acto del Piching es: el arte de comunicar (sea verbalmente o literalmente) la esencia de su historia o proyecto a un agente, ejecutivo del estudio o productor, como un medio de incitar a los compradores potenciales para leer sus escrituras completas. Hay reglas que establecen estas sesiones y van de la limitante de 3 a 5 minutos de exposición, y el síntoma más común es que el participante domine estadios básicos como su comportamiento físico, su estructurada exposición, su conocimiento previo de los productores que intervienen y la convicción personal de que su historia merece ser producida. En estas sesiones no se permite desarrollar la historia completa, se trata de conceptuar todo dejando elementos intrigantes para que los asistentes se interesen en saber el resto y le pidan un tratamiento de su historia o en el mejor de los casos el primer Draft del guión.

Las sesiones comienzan registrándose personalmente en un Pitch Room y donde se hace conocer ciertos reglamentos inviolables y se explica el funcionamiento estructural de la sesión y todos los NO, que incluyen: no pasarse del tiempo establecido y no pedir concesiones de tiempos extras, esta sola insinuación será asumida como una mala exposición. No dejar información impresa si no se solicita (generalmente no se solicita en el lugar, si quieren contactarlo se lo harán saber) y un NO muy particular: no utilizar recursos exagerando ganchos expositivos como, por ejemplo; interpretar a su personaje central mientras está desarrollando el Pitch.

Conciente que el momento es único, no es fácil pre- pararse para la primera vez. Lo que buscan de uno es que la historia fluya, progrese e interese como para pedir una audición personal en un estudio o el escalonado y puntual pedido de trabajos tendentes a cotejar el potencial de la historia mas de cerca. En todo caso, nuestro trabajo comienza a ser remunerado a partir del primer pedido de un productor 0 ejecutivo de estudio.

Los productores y agentes suelen oír 4.500 Pitchs en una sesión. Si una idea en particular es atrayente para ellos, no sólo solicitarán un meeting o un encargo sino que querrán saber si "hay algo mas" detrás de este descubrimiento y ese "algo mas" significa otros proyectos escritos que garanticen que no sólo tenemos este Pitch. En estas reuniones no sólo se puede encontrar un potencial comprador de los derechos, también podemos toparnos con un agente que quiera representarnos, mas allá que esto no signifique una remuneración inmediata, en Estados Unidos tener un buen agente significa sumar prestigio y posibilidades de que su material tenga circulación más allá de estos encuentros. Si la sesión ha sido bien expuesta querrán saber si realmente somos prolíficos o tuvimos el "touch" de diosa fortuna en un solo Pitch.

Es mejor que antes de ir a una sesión de Pitch no sólo nos preparemos para esta historia específica sino que pongamos en orden otros proyectos postergados, porque pueden ser la prueba de que no somos improvisados y que dominamos géneros diversos. En la construcción de una obra hay procesos traumáticos difíciles de sobrellevar, son procesos de recomposición permanente hacia el arraigo definitivo del caos. Es difícil explicar como el uso del Pitch proporciona valor a la creación y fomenta la inspiración en situaciones catárticas.

En todas y cada una de las circunstancias hay un punto de partida, un origen de la voluntad 0 un deseo de realizar un film, de servirlo o servirse de él. Importa saber entonces qué se quiere y orientar la acción en el sentido más adecuado, con las formas y técnicas al alance real de las posibilidades concretas de filmar y exhibir lo filmado.

Lo expresa Federico Fellini: "la fantasía nos sumerge con sugestiones, en todo momento y en todas las direcciones. Lo necesario para dar forma precisa a esa fantasía, es encontrar el pretexto; crearse lazos con la realidad material, sin lo cual jamás daría forma concreta a mis ideas..."

\section{Bibliografía}

Katz, S. D. (1991). Shot by Shot: Visualizing from concept to screen, Studio City, CA, Michael Wise Production. Truby, J.(2003). Secrets of Blockbuster M ovies - Deep Structure, Burbank, CA, Writerstore.

Phillips, M. A.(2002) Dramatica: A New Theory Of Story By Melanie Anne Phillips and Chris Huntley, Chapter 11, Problem Solving and Justification, Deep Theory, Storymind. Tarkovski, A. (1991) Esculpir en el Tiempo. Madrid: Ediciones Rialp.

Caveing, M. La dialecticque du concept au cinema,

Revue de filmologie, 2.

Payan, M.J, (s/f) David Lynch, .Madrid: Ediciones JC. 